IRA-International Journal of Applied Sciences ISSN 2455-4499; Vol.03, Issue 03 (2016)

Institute of Research Advances

http://research-advances.org/index.php/IRAJAS

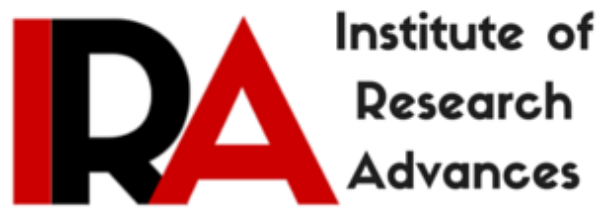

\title{
Clinical Profile of Cutaneous Adverse Drug Reactions in a Tertiary Care Centre
}

\author{
${ }^{1}$ Priya Prathap, ${ }^{2}$ Elsy M.I, ${ }^{2}$ Ajitha K. N, ${ }^{1}$ Ajith Kumar, ${ }^{1}$ Sandhya George \\ ${ }^{1}$ Dept of Dermatology \& Venereology, \\ Govt Medical College Thrissur. \\ 2 Dept of Pharmacology, \\ Govt Medical College Thrissur.
}

DOI: http://dx.doi.org/10.21013/jas.v3.n3.p12

\section{How to cite this paper:}

Prathap, P., M.I, E., K. N, A., Kumar, A., \& George, S. (2016). Clinical Profile of Cutaneous Adverse Drug Reactions in a Tertiary Care Centre. IRA-International Journal of Applied Sciences (ISSN 2455-4499), 3(3). doi:http://dx.doi.org/10.21013/jas.v3.n3.p12

(C) Institute of Research Advances

\section{(cc) EY-NC}

This works is licensed under a Creative Commons Attribution-Non Commercial 4.0 International License subject to proper citation to the publication source of the work.

Disclaimer: The scholarly papers as reviewed and published by the Institute of Research Advances (IRA) are the views and opinions of their respective authors and are not the views or opinions of the IRA. The IRA disclaims of any harm or loss caused due to the published content to any party. 


\section{ABSTRACT}

Context: Cutaneous adverse drug reactions (cADR) constitute 2-3\% of all hospitalized patients. However there is paucity of data regarding occurrence of cADR among out patients. Hence we decided to do a study on clinical profile of cADR and to find out the common drugs resulting in $c A D R$.

Objective: To observe the clinical spectrum and the causative drugs of cADR among patients attending Dermatology Department in our hospital.

Methods: Patients with cADR who attended Dermatology Out Patient Department $(O P D)$ in our institution were studied for a period of one year.

Results:71 patients were diagnosed to have cADR. Male to female ratio was $1.15: 1$. Maculopapular rash $(22 / 71 ; 31 \%)$ was the commonest presentation followed by generalised pruritus $(16 / 71 ; 22.5 \%)$, fixed drug eruption( FDE) ( $8 / 71 ; 11.3 \%)$ and urticaria $(5 / 71 ; 7 \%)$. Antimicrobials $(40.8 \%)$, NSAIDS $(22.5 \%)$ and Antiepileptics $(22.5$ $\%)$ were the common drugs responsible for these eruptions.

Key words : antibiotics, antiepileptics, drug reactions

Introduction: Cutaneous adverse drug reactions are the most frequently reported type among all drug reactions[1]. A systematic review of cADR in Indian population showed the incidence as 9.22/1000 among outpatient and inpatient cases [2]. They may affect quality of life especially in serious drug reactions like SJS and TEN. Drug reactions may also mimic diseases like viral exanthems and systemic lupus erythematosus, resulting in unnecessary investigations and delay in treatment. The morphological patterns of cADR vary from benign maculopapular rash to fatal toxic epidermal necrolysis. Therefore, prompt diagnosis and treatment as well as future avoidance of the medication are essential to reduce morbidity and mortality. So we did a study to assess the clinical features of cADR and the drugs responsible for the same among out patients attending our institution.

Subjects and Methods: Cases of cADR who attended Dermatology Department, Govt Medical College Thrissur, Kerala for a period of one year were studied. Detailed history including age, sex, duration, past history and family history of drug reaction , any systemic disease and drugs taken by the patient were recorded. General and systemic examination was done. All patients were examined by the dermatologist and the morphological pattern of drug reaction identified. We have used WHO causality assessment method for diagnosis of drug reaction [3]. As per WHO causality assessment method, "certain"/"definite" category of ADR is based on-plausible time relationship to drug administration, known pharmacology of drug, absence of alternative explanation by underlying disease or concomitant drug (s), positive de-challenge and re-challenge. The "probable" category of ADR is based on all of the above criteria except re-challenge information is not required. Patients with diagnosis of "probable" ADR according to WHO causality assessment were included in the study. Patients who were not willing to participate in the study and those not belonging to the "probable" class of ADR were excluded from the study. Blood routine was done in all patients . Liver and renal function tests and other relevant investigations were done based on history and clinical examination. Challenging with suspected drug was done only if it is of benefit to the patient. 
Results: 14,047 new patients attended Dermatology OPD over a period of one year among which 71 patients $(0.5 \%)$ had cADR . Male to female ratio was 1.15:1.The common age groups with cADR observed were between 40-59 years $(36.6 \%)$ followed by 20-39 years $(29 \%) .10 \%$ of cases ( 7 patients) belonged to $<12$ years of age and elderly (> 60 years old ) constituted $10 \% .32$ patients $(45 \%)$ were on multiple drugs. Seven patients $(9.9 \%)$ had family history of drug reaction, the details regarding the drugs which caused the drug reaction not known. None of the patients had past history of drug reaction.

Clinical types of cADR observed in our study are shown in figure 1.

Clinical picture of a patient with Toxic Epidermal Necrolysis (TEN) is shown in figure 2.

Drugs which resulted in cADR are shown in Table 1.

Eosinophilia was present in 13 patients (18.3\%). All the10 patients( $14.1 \%)$ with severe types of cADR like SJS and TEN had elevated liver enzymes. 2 patients with TEN developed septicaemia but managed with antibiotics. Prognosis was good even in severe type of drug reactions except for ocular complication (corneal opacity) in one patient with TEN. No mortality occurred.

Discussion: In our study, the occurrence of cADR among out patients $(0.5 \%)$ was found to be similar to the study conducted in a tertiary care centre in Malaysia $(0.86 \%)$ [4]. But certain other studies have reported a higher incidence, $2.6 \%$ in a study conducted in North India [5] and $1.5 \%$ and $1.38 \%$ respectively in some other studies [6,7].The lower incidence of cADR in our study may be due to the fact that being a tertiary care centre only doubtful and serious cases had attended our hospital. Some studies had reported a higher frequency in women [8,9] whereas some other studies have noticed higher occurrence in men $[10,11]$. But in our study, no such preponderance was noticed $(\mathrm{M}: \mathrm{F}=1.15: 1)$.

Regarding risk factors for cADR, positive family history and patients on multiple drugs may have a role. Family history of cADR was present in $5.42 \%$ of patients in the systematic review whereas $9.9 \%$ in our study [2]. 32 patients (45\%) in our study were on multiple drugs. In such cases there is chance for alteration in metabolism of drugs as a consequence of which drug reaction may occur.

The order of pattern of cADR observed was different in various studies.In our study, the most frequent pattern identified was maculopapular rash followed by generalized pruritus and FDE . This morphological pattern was the predominantly recognised one in some previous studies $[2,8]$. Commonly observed reactions were maculopapular rash (32.39\%), fixed drug eruptions (FDEs) $(20.13 \%)$, urticaria (17.49\%) and Stevens-Johnson syndrome/toxic epidermal necrolysis (SJS/TEN) (6.84\%)in the systematic review of cADR in Indian population [2]. Incidence of urticaria was lesser in our study (7\%) compared to another study (21.5\%) [1]. FDE was the most common drug eruption followed by maculopapular rash in the study conducted in Pondicherry [9]. This variation in clinical pattern could be due to different type of drug usage and different ethnic group characteristics. SJS-TEN was reported in large number of patients (14\%) in our study compared to other studies [12]. This may be because ours is a tertiary care centre with a wide drainage area with patients coming from about three districts. 
Among the drugs which were responsible for cutaneous reactions, antimicrobials $(40.8 \%)$ were the chief culprit identified as in earlier studies $[2,8,12,13]$ followed by NSAIDs (22.5\%) and antiepileptics (22.5\%).Serious cutaneous reactions like SJS and TEN were noticed mostly in patients receiving antiepileptics (8/10), the drugs were carbamazepine (5 cases), Phenytoin ( 2 cases) and one case due to Sodium Valproate. Two patients on anti retroviral therapy (ART) with Zidovudine, Lamivudine and Nevirapine developed SJS about 3 weeks after starting the treatment.

Drug challenge was done for the five patients on ATT who presented with maculopapular rash and the culprit drug identified which was INH in 3 patients and Ethambutol in 2 patients.

Limitation of our study was that since it was conducted in a tertiary care centre, the result could not be generalised to the population.

Regular studies on cADR in each region is important to document the changes in the clinical patterns and to know regarding the culprit drugs which will help clinicians to anticipate and modify the prescription pattern. 
(Tables \& Figures)

Fig 1 : Clinical types of cADR

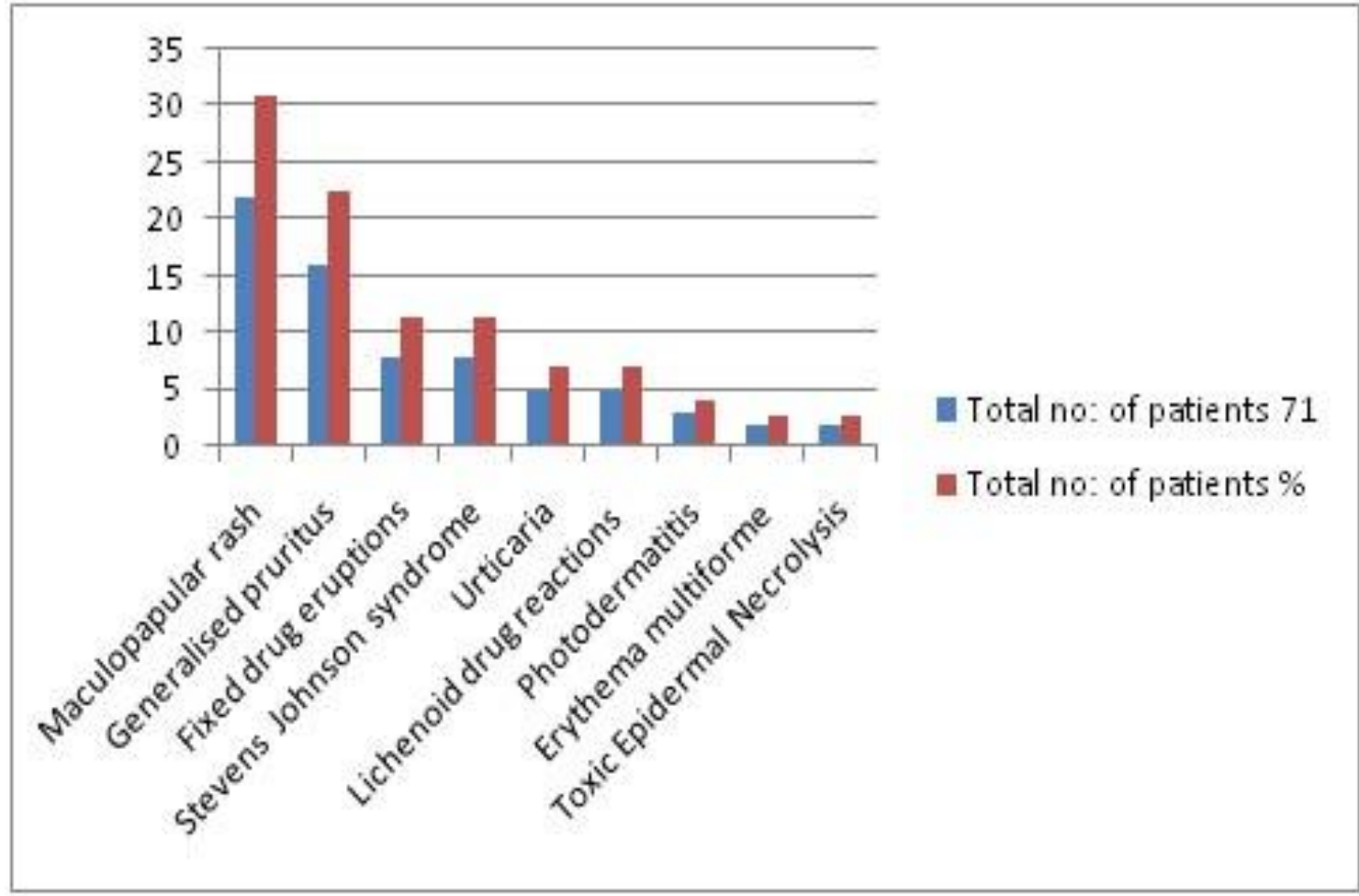

Fig 2 : Toxic epidermal necrolysis

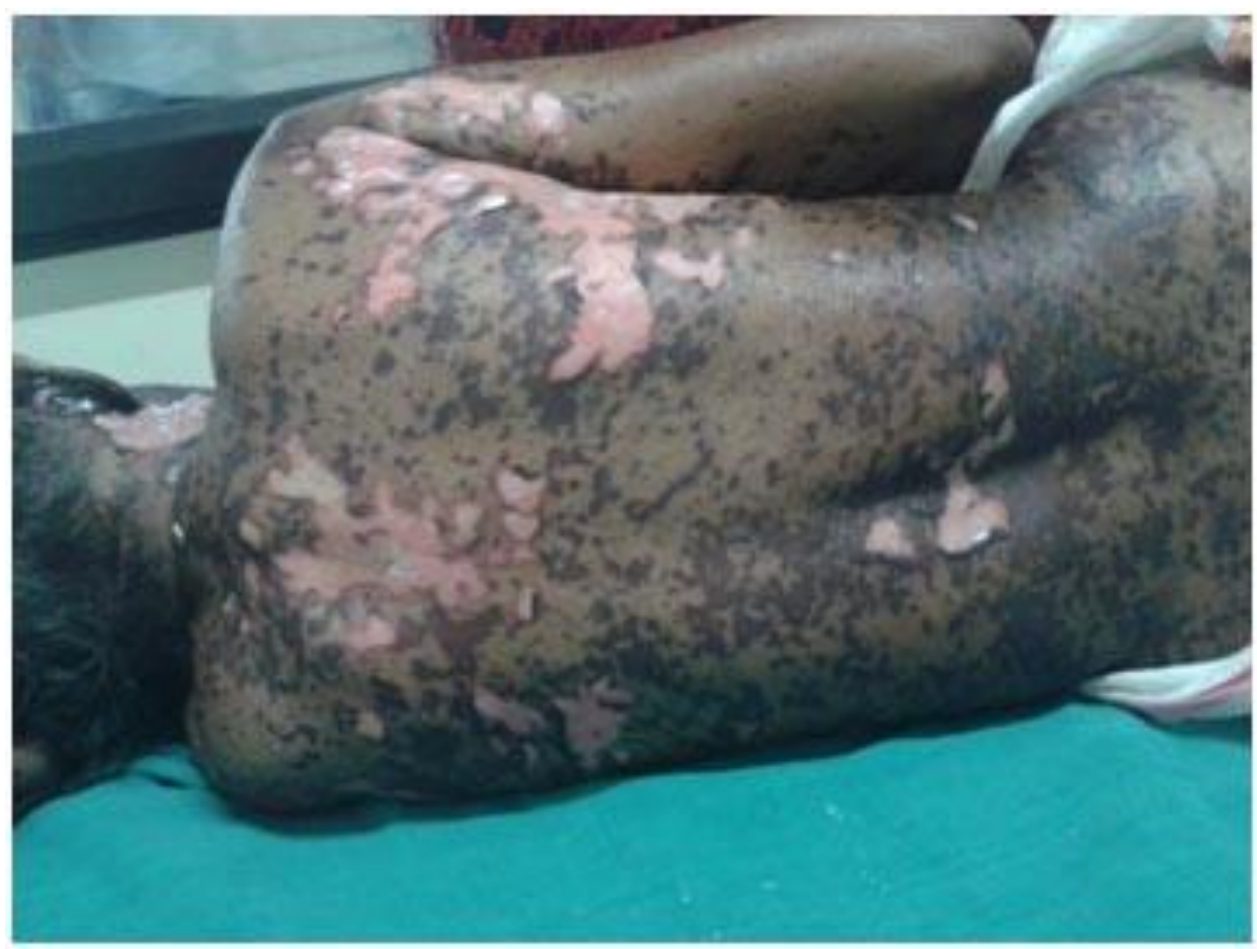


Table 1 : Drugs implicated in cADR

\begin{tabular}{|c|c|c|}
\hline Drug & Total & $\%$ \\
\hline & $\begin{array}{l}71 \\
\text { cases }\end{array}$ & \\
\hline Antimicrobials & $\begin{array}{l}29 \\
\text { cases }\end{array}$ & 40.8 \\
\hline Penicillin & 7 & 24.1 \\
\hline ATT(Anti tuberculosis therapy) & 5 & 17.2 \\
\hline Antifungals(Fluconazole,Griseofulvin) & 5 & 17.2 \\
\hline Quinolones & 4 & 13.8 \\
\hline Co trimoxazole & 4 & 13.8 \\
\hline Doxycycline & 2 & 6.9 \\
\hline ART(Anti retroviral therapy) & 2 & 6.9 \\
\hline NSAIDS & $\begin{array}{l}16 \\
\text { cases }\end{array}$ & 22.5 \\
\hline Diclofenac & 6 & 37.5 \\
\hline Ibuprofen & 3 & 18.8 \\
\hline Paracetamol & 3 & 18.8 \\
\hline Piroxicam & 2 & 12.5 \\
\hline Indomethacin & 2 & 12.5 \\
\hline Antiepileptics & $\begin{array}{l}16 \\
\text { cases }\end{array}$ & 22.5 \\
\hline Carbamazepine & 7 & 43.8 \\
\hline Phenytoin & 7 & 43.8 \\
\hline Valproate & 1 & 6.25 \\
\hline Phenobarbitone & 1 & 6.25 \\
\hline Antimetabolites(Methotrexate, Cyclophosphomide) & 5 & 7.04 \\
\hline Anti diabetic (Daonil) & 3 & 4.2 \\
\hline Statin (Atorvostatin) & 2 & 2.8 \\
\hline
\end{tabular}




\section{References:}

1.JhajR, Uppal R.Cutaneous adverse reactions in in-patients in a tertiary care hospital.Indian J Dermatol Venereol Leprol 1999;65:14-7.

2.Patel TK, Thakkar SJ, Sharma DC. Cutaneous adverse drug reactions in Indian population: A systematic review. IDOJ 2014;5:76-86.

3. The use of the WHO-UMC system for standardized case causality assessment. Accessed from: http://www.WHO-UMC.org/graphics/4409.pdf

4. Choon S, Lai N. An epidemiological and clinical analysis of cutaneous adverse drug reactions seen in a tertiary hospital in Johor, Malaysia. Indian J Dermatol Venereol Leprol $2012 ; 78: 734-739$.

5. Chatterjee S, Ghosh AP, Barbhuiya J, Dey SK. Adverse cutaneous drug reactions: A one year survey at a dermatology outpatient clinic of a tertiary care hospital. Indian $\mathbf{J}$ Pharmacol. 2006;38:429-31.

6. Zaraa I, Jones M, Trojjet S, Rouhou RC, Euch DE, Mokni M, et al. Severe adverse cutaneous drug eruptions: Epidemiological and clinical features. Int J Dermatol 2011;50:877-80.

7.Borch JE, Andersen KE, Bindslev-Jensen C. Cutaneous adverse drug reactions seen at a University hospital Department of Dermatology. Acta Derm Venereol 2006;86:523-7.

8. Arndt KA, Jick H.Rates of cutaneous reactions to drugs: A report from the Boston Collborative Drug surveillance Program. JAMA 1976; 235;918-92.

9.Pudukadan D, Thappa D M .Adverse Cutaneous drug reactions: clinical pattern and causative agents in a tertiary care center In SouthIndia. Indian J Dermatol Venereol Leprol 2004;70:20

10.Rahska MP, Marfatia YS. Clinical study of cutaneous drug eruptions

in 200 patients. Indian J Dermatol 2008;74:74-80.

11.Fiszenson-Albala F, Auzerie V, Mahe E, Farinotti R, Durand-Stocco C, Crickx B, et al. A 6-month prospective survey of cutaneous drug reactions in a hospital setting. $\mathrm{Br} \mathrm{J}$ Dermatol 2003;149:1018-22.

12.Kauppinen K ,Stubble S.Drug eruptions:Causative agents and clinical types.A series of in-patients during a 10 year period. Acta DermVenereol 1984;64:320-324.

13. Sharma VK,Sethuraman G, KumarB. Cutaneous adverse drug reactions:Clinical pattern and causative agents- A six year series from Chandigarh, India. J Postgrad Med 2001;47;95-97. 